\title{
LA VEJEZ DESDE LA MIRADA DE LOS JÓVENES CHILENOS: ESTUDIO EXPLORATORIO
}

\author{
MARCELO ARNOLD-CATHALIFAUD* \\ DANIELA THUMALA** \\ ANAHÍ URQUIZA*** \\ ALEJANDRA OJEDA****
}

\begin{abstract}
RESUMEN
Esta investigación buscó conocer la mirada que los jóvenes chilenos, en este caso universitarios, tienen sobre la vejez. El trabajo está basado en corrientes del pensamiento gerontológico que destacan que en gran medida las minusvalías de las personas mayores son producto de su exclusión social y de un contexto cultural desfavorable, más que de su estado físico o condición mental. De qué manera se dan estas exclusiones fue el objeto de una investigación realizada entre jóvenes chilenos, a partir de la aplicación de una prueba de diferencial semántico a 682 estudiantes universitarios. El propósito del estudio fue ampliar el conocimiento sobre las imágenes que los jóvenes universitarios chilenos tienen de la vejez y proponer, a la luz de sus resultados, una reflexión sobre algunas de las consecuencias que estas imágenes pueden tener en nuestra sociedad. Los resultados mostraron un predominio de imágenes negativas que son generalizadas y proyectadas sobre la vejez, las que podrían estar afectando las perspectivas de bienestar de los adultos mayores actuales y futuros en un contexto creciente de envejecimiento poblacional y aumento de las expectativas de vida.
\end{abstract}

Palabras clave: Chile, Jóvenes, ImÁgenes sociales, VeJez

* Director Observatorio Social de la Vejez y Envejecimiento en Chile. Universidad de Chile, Facultad de Ciencias Sociales, Santiago, Chile. Correo electrónico: marnold@uchile.cl.

** Directora ejecutiva Fundación SOLES. Correo electrónico: dthumala@soles.cl.

*** Académica Programa de Magíster en Antropología y Desarrollo, Departamento de Antropología, Universidad de Chile, Santiago, Chile. Correo electrónico: anahiurquiza@gmail.com.

**** Académica Programa de Magíster en Antropología y Desarrollo, Departamento de Antropología, Departamento de Antropología, Universidad de Chile, Santiago, Chile.

Correo electrónico: alejandra.ojeda.mayorga@gmail.com. 


\section{RESUMO}

\section{A VELHICE NA ÓTICA DOS JOVENS CHILENOS: ESTUDO EXPLORATÓRIO}

Esta pesquisa buscou conhecer o olhar dos jovens chilenos, neste caso universitários, sobre a velhice. O trabalho está baseado em correntes de pensamento gerontológico que destacam que, em grande medida, as deficiências das pessoas idosas são produto de sua exclusão social e de um contexto cultural desfavorável, mais do que de seu estado físico ou condição mental. De que maneira se dão estas exclusões foi o objeto de uma pesquisa realizada entre jovens chilenos, a partir da aplicação de uma prova de diferencial semântico a 682 estudantes universitários. O propósito do estudo foi ampliar o conhecimento sobre as imagens que os jovens universitários chilenos têm da velhice e propor, à luz de seus resultados, uma reflexão sobre algumas das conseqüências que estas imagens podem ter em nossa sociedade. Os resultados mostraram um predomínio de imagens negativas que são generalizadas e projetadas sobre a velhice, as quais podem estar afetando as perspectivas de bem-estar dos idosos da atualidade e do futuro, em um contexto crescente de envelhecimento populacional e aumento das expectativas de vida.

Palavras chave: Chile, Jovens, Imagens sociais, Velhice

\section{Abstract}

\section{OLD AGE FROM THE VIEW OF CHILEAN YOUTH: EXPLORATORY STUDY}

This investigation searched for the view that the Chilean youth, in this case university students, have on old age. The work is based on the movements of the gerentological thought which to a great extent emphasizes minusvalias in older people which is a product of their social exclusion and unfavorable cultural context, more than of their physical state or mental condition. These exclusions were the object of an investigation made among Chilean youth, by applying a semantic differential test to 682 university students. The intention of the study was to extend the knowledge of the images that the Chilean university students have of old age and propose, a reflection on some of the consequences that these images can have in our society. The results showed a predominance of negative images that are generalized and projected on old age, those that could be affect the perspective of well-being of present and future of the old aged in an increasing context of population aging and increase of the life expectancies.

Key words: Chile, Youth, Social IMAges, Old Age 


\section{INTRODUCCIÓN}

ACTUALMENTE CHILE CUENTA CON una población de 16.3 millones de habitantes y se encuentra en un importante proceso de cambio demográfico, el cual se traduce en un considerable impacto en las estructuras sociales tradicionales. Nuestro país envejece aceleradamente, destacándose en tal sentido dentro la región latinoamericana. La fecundidad ha disminuido y está llegando a un nivel por debajo del de reemplazo (Bravo y Bertranou, 2006). Se observan menores tasas de mortalidad y la esperanza de vida en nuestro país, de acuerdo con el Instituto Nacional de Estadísticas, alcanza hoy día alrededor de los 78 años, lo que representa un incremento de más de 20 años en las últimas cinco décadas.

De acuerdo con Aguilera (2005) en el año 2005 las personas mayores de 65 años constituían el 7,93\% de la población y en el 2050 se estima que llegarán al $21,59 \%$. Actualmente, los adultos mayores de sesenta años suman un total de 1.717 .478 personas. Al considerar las proyecciones mencionadas, la población mayor estaría, en un breve tiempo, ocupando un espacio relevante en la estructura de nuestra sociedad desplazando a la cohorte de los menores de quince años.

Este aumento de población mayor genera una serie de interrogantes que destacan la complejidad de este fenómeno. Una de ellas tiene que ver con las imágenes y expectativas sobre la vejez que se instalan en nuestra sociedad y sus consecuencias. Estas imágenes tienen relación con la manera en que este grupo es integrado y valorado, con la forma en que los actuales adultos mayores perciben y experimentan su etapa de vida; y, especialmente, en cómo las nuevas generaciones, los jóvenes particularmente, prefiguran su propia vejez.

Aún cuando las imágenes sociales sobre la vejez no presentan un carácter universal, los estudios coinciden en señalar que éstas contienen estereotipos con fuertes cargas negativas, alejándose así de lo que los adultos mayores pudieran efectivamente esperar ante los avances de la modernidad que han dado lugar a sus actuales expectativas de vida. Una investigación realizada en España entre los años 2002 y 2003 (Adelantado et al., 2004) mostró como las imágenes generalizadas en torno a la vejez están lejos de representar lo que los mismos ancianos piensan y sienten respecto de ésta y de la forma en como ellos mismos se representan el transitar por dicha etapa. Otros ejemplos, señalados por Tan et al. (2004), muestran cómo en Estados Unidos, en el Sudeste de Asia y en el Caribe la vejez es asociada con rasgos negativos, tales como «triste», «inflexible», «no atractiva», por 
mencionar algunos. Una investigación realizada en Nigeria (Okoye, 2004) orientada a indagar el conocimiento que los jóvenes nigerianos tienen sobre la vejez, en un país donde la expectativa de vida alcanzará los 64 años en el año 2025, mostró que, pese a que los jóvenes nigerianos tienen poca experiencia de convivencia con personas mayores, han desarrollado fuertes estereotipos negativos hacia éstas. La literatura especializada consigna pocas excepciones a estas atribuciones, entre las cuales se destaca un estudio sobre la percepción que los estudiantes universitarios chinos tenían de los adultos mayores (Tan et al., 2004), el cual observó que los estudiantes tenían actitudes positivas o neutrales hacia los adultos mayores. Los autores atribuyen a la cultura local la positiva actitud que tienen los jóvenes hacia los adultos mayores, ya que en el confusionismo - que está en la base de sus premisas culturales - se le da especial valor a lo tradicional.

En Chile, el Comité Nacional para el Adulto Mayor realizó, durante el año 2002, un estudio sobre la imagen de la vejez de los estudiantes de enseñanza secundaria. Para ello aplicó una encuesta orientada a conocer la percepción de los jóvenes sobre los adultos mayores. La muestra correspondió a 164 estudiantes de cinco colegios mixtos de la Región Metropolitana, los que estaban cursando el Tercer Año Medio, cuyas edades fluctuaron entre los 15 y 18 años. Si bien se observaron algunas tendencias positivas a la hora de evaluar a los adultos mayores, la presencia de estereotipos negativos fue evidente. Por esta razón, el Comité concluyó que era urgente, en el marco de políticas públicas, revertir las imágenes y actitudes negativas hacia el adulto mayor (Informe del Comité Nacional para el Adulto Mayor, 2002).

Si bien es posible observar en algunos contextos imágenes positivas de los adultos mayores, la tendencia es percibir la vejez como una etapa en la que se pierden los atributos positivos de la vida. La mayoría de los estudios disponibles muestran que las imágenes que construyen los jóvenes sobre la vejez, en general se asocian a una valoración negativa de esta etapa de la vida. Las investigaciones coinciden en mencionar que los estereotipos se concentran en la pérdida de capacidades de las personas mayores; destacan que la postura conservadora se va radicalizando a medida que pasan los años, que los intereses por la sexualidad decaen o desaparecen y que habría crecientes dificultades para adaptarse a los nuevos contextos sociales y tecnológicos. A partir de estas imágenes es factible suponer que, para los jóvenes, su relación con las personas viejas puede implicar una tarea de la que hay que hacerse cargo. 
Al respecto, de acuerdo con los resultados de una reciente encuesta nacional (Bicentenario UC-Adimark, 2006) en Chile la mayoría de las personas sostiene que al envejecer los padres, los hijos deberían hacerse cargo económicamente de ellos. En todo caso, es interesante observar que son los jóvenes quienes mayoritariamente, en un $68,4 \%$, comparten la idea de tener que hacerse cargo de los mayores, más que éstos mismos, quienes sólo en un 56\% lo consideran de esta forma. A modo de síntesis, la tendencia en lo que respecta a las imágenes de la vejez, es suponer que «tras las fases de crecimiento, de madurez y de apogeo, viene la decadencia» (Puijalon y Trincaz, 1999). En concordancia con lo señalado, no es extraño suponer que existe una idealización de la juventud y la adultez temprana, ya que estas etapas de la vida, son vistas como las únicas en que es posible la realización personal, el éxito o mayores posibilidades de encontrar la felicidad. Paradojalmente, por el aumento de la esperanza de vida, la juventud y la adultez tienden a ser proporcionalmente períodos cada vez más breves dentro del ciclo vital.

La relevancia de nuestra investigación consiste en que, a la luz de los cambios demográficos descritos, nuestra sociedad debe aprender a convivir cada vez con más viejos y también, en las circunstancias actuales, éstos se ven obligados a aprender a comportarse acorde a las expectativas que difusamente se configuran en sus contextos sociales. Estas expectativas, expresadas en representaciones sociales, concentran concepciones e imágenes que norman lo que se espera de los distintos grupos de edad y conllevan fuertes valoraciones. Específicamente, las referidas a la vejez pueden convertirse, como señalan algunos gerontólogos (Young y Schuller, 1993), en medios opresivos que obligan a las personas a ajustarse a roles extremadamente estereotipados.

\section{MARCO TEÓRICO}

Es un lugar común señalar, desde la mirada de las ciencias sociales que, en tanto la realidad social emerge desde procesos autorreferidos, las imágenes y representaciones compartidas que se tienen sobre un grupo etario afectan la manera particular de relacionarnos con éste, pues favorecen la confirmación de las expectativas que contienen. Una suerte de profecía autocumplida reproduce estilos discriminatorios de relación. Específicamente, la heteropercepción sobre el adulto mayor conduce a una autopercepción que afecta su propia autoestima (Gómez Carroza, 2003:181), vale decir, esta dinámica finalmente incluye 
a los propios involucrados: los adultos mayores también terminan representando las imágenes desfavorecidas sobre su etapa de vida y se comportan consistentemente con ellas. Es en este sentido que, aún cuando la mayor duración de la vida humana puede señalarse como un importante logro de la modernidad, éste se comunica como uno de los problemas más grandes del nuevo milenio, no solamente para la sociedad mundial, sino también para la mayoría de las personas que envejecen.

Nuestro punto de partida fue indagar cómo son percibidos los adultos mayores y preguntarnos sobre cuáles son y de qué se componen las imágenes que la juventud notifica, en nuestra sociedad, sobre la vejez. Específicamente, nuestros objetivos consistieron en identificar las formas de distinción que los jóvenes aplican a la condición de vejez.

El estudio se basó en una propuesta teórica vinculada estrechamente con los planteamientos sistémicos y constructivistas, los cuales sostienen que todo lo que se produce y reproduce como conocimiento, incluyendo imágenes, estereotipos o expectativas, remite a operaciones de observación determinadas por las posibilidades y condiciones presentes en la sociedad (Luhmann, 1998). Específicamente se sostiene que la estructura de la sociedad es una variable significativa para poder entender los problemas que se asocian a la vejez. Desde esta perspectiva, denominada Programa sociopoiético de observación (Arnold, 2003) se pueden describir las diferentes racionalidades constituyentes de la realidad social y reconocer la aguda diferenciación de la sociedad, lo cual estimula el entendimiento de fenómenos complejos que carecen de referencias unívocas. Basados en este Programa, descartamos de plano la posibilidad de encontrar formas únicas de vivenciar la vejez. Como es propio a todo lo humano y a lo social, existirían tantas formas de vejez como sean posibles de ser distinguidas.

Desde enfoques equivalentes, el sociólogo español Juan Luis Pintos (2004) define objetos de observación similares a los nuestros, como imaginarios sociales, es decir, esquemas socialmente construidos en la comunicación social. Entre las funciones que tendrían estos esquemas, estaría la producción de estabilidad en las relaciones sociales y la generación de explicaciones globales a fenómenos fragmentarios y disímiles. Bajo esta perspectiva, los roles se conformarían por el conjunto de conductas, actitudes e ideas que se esperan de un determinado tipo de personas y que son subsidiarias de tales distinciones, como es el caso de las categorías de edad. 
El programa sociopoiético es apropiado para observar la vejez, debido a que las atribuciones con que se designan los contenidos vivenciales y experienciales de cada etapa de la vida, se producen desde esquemas de distinción, a partir de los cuáles se forman las expectativas sociales que aumentan las probabilidades de que las comunicaciones y acciones que las reproducen sigan ciertas direcciones y no otras. En este sentido resulta interesante observar en las comunicaciones de nuestra sociedad cómo se caracteriza la vejez, en tanto las formas de distinguir siempre se empalman con expectativas tipificadas de comportamientos.

\section{Metodología}

Para registrar y conocer las distinciones que se aplican a la vejez se construyó una prueba del tipo diferencial semántico (Osgood et al, 1957). Esta técnica resulta particularmente útil para estudios que se basan en comunicaciones. El instrumento estuvo compuesto por una serie de pares de adjetivos, generados a partir de la literatura especializada, que permiten discriminar atribuciones sobre la vejez. Para seleccionar los adjetivos que finalmente conformaron el instrumento, la prueba fue testeada en una aplicación piloto a una muestra de 60 estudiantes universitarios y cuyos resultados fueron sometidos a la evaluación de expertos. A partir de este proceso se seleccionaron los siguientes pares de adjetivos: independiente/dependiente; productivo/improductivo; eficiente/ineficiente; hábil/torpe; saludable/enfermizo; sexualmente activo/sexualmente no activo; frágil/resistente; sociable/retraído; tolerante/intolerante; confiado/desconfiado; progresista/conservador; no conflictivo/conflictivo; ciudadano activo/ciudadano pasivo; protegido/de-samparado; integrado/marginado y valorado/desvalorado. Estos adjetivos se proyectaron como escalas bipolares frente a los estatuses de Adulto Mayor, Anciano y Anciana, que para efecto de este tipo de prueba, cumplen la función de reactivos. Los promedios de edad estimados para Anciana y Anciano fueron los 70 años, mientras que para Adulto Mayor el promedio fue de 61 años, ${ }^{1}$ edad en que muchas personas aún no jubilan y se encuentran en plena etapa productiva. Por

1 En el instrumento aplicado se agregó una pregunta abierta para que los estudiantes indicaran la edad que le atribuían a los adultos mayores, ancianas y ancianos. A partir de esto hemos logrado vincular las imágenes que se construyen con una edad cronológica asociada a ellas. 
último, tanto los pares de adjetivos como la ubicación de los aspectos «positivos» $\mathrm{y}$ «negativos» de cada par, fueron ordenados aleatoriamente.

Finalmente, se fijó una distancia de 7 puntos entre sus versiones extremas, para que así los encuestados pudieran marcar a qué distancia de cada extremo ubicaban a cada uno de los reactivos para los 16 pares de adjetivos presentados. La estrategia de recolección de datos consistió en la aplicación de un cuestionario autoadministrado con instrucciones a seguir, como se muestra en el siguiente cuadro.

Cuadro 1

Formato de la prueba diferencial semántico

\begin{tabular}{|c|c|c|}
\hline \multicolumn{3}{|c|}{$\begin{array}{c}\text { REACTIVO } \\
\text { (Adulto Mayor, Anciana, Anciano) }\end{array}$} \\
\hline Independiente & ப口ロロாПப & Dependiente \\
\hline Productivo & 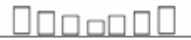 & Improductivo \\
\hline Saludable & 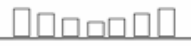 & Enfermizo \\
\hline Intolerante & 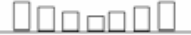 & Tolerante \\
\hline Eficiente & 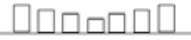 & Ineficiente \\
\hline Frágil & 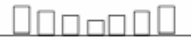 & Resistente \\
\hline Progresista & 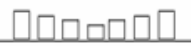 & Conservador \\
\hline Ciudadano pasivo & 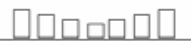 & Ciudadano activo \\
\hline Desamparado & 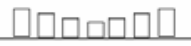 & Protegido \\
\hline Sexualmente activo & 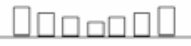 & Sexualmente no-activo \\
\hline Habbil & 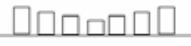 & Torpe \\
\hline Integrado & 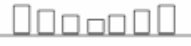 & Marginado \\
\hline Confiado & 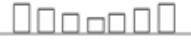 & Desconfiado \\
\hline Conflictivo & 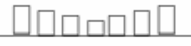 & No conflictivo \\
\hline Sociable & 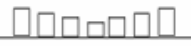 & Retraido \\
\hline Valorado & 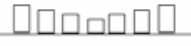 & Desvalorado \\
\hline
\end{tabular}

Con respecto al diseño muestral, éste fue de naturaleza no probabilística, basándose específicamente en el modelo de muestreo por conveniencia que opera desde la selección no aleatoria de unidades bajo criterios de contactación en grupos que forman parte del universo definido como objetivo y cuya disponibilidad es la más conveniente para los fines investigativos (Zikmund, 1998). El universo teórico del estudio correspondió a estudiantes de Educación Superior Universitaria de pre-grado de instituciones pertenecientes al Consejo de Rectores 
de las Universidades Chilenas que tengan sede en la Región Metropolitana. Pero, al utilizarse una muestra cautiva de alumnos de los Cursos de Formación General que se imparten en la Universidad de Chile, el universo real se delimitó a este grupo. Considerando que el total de la matrícula de alumnos del universo real es 87.923, la Universidad de Chile alcanza al $24 \%$ del total (24.502 alumnos de pre-grado). El tamaño de la muestra en tanto, alcanzó a 682 alumnos. Si bien se trata de una muestra generada en base a un diseño no probabilístico, la simulación del cálculo de error indica que de tratarse de una muestra aleatoria su margen de error hubiese sido $+-3,7 \%$ bajo supuesto de máxima varianza.

En términos más específicos, la muestra se compuso de un 50,3\% de hombres y $49,7 \%$ de mujeres, proporción similar al parámetro nacional y a la matrícula de alumnos de pre-grado de la Educación Superior Universitaria del país. La menor edad de los encuestados fue 17 años y la mayor alcanzó a 25 años (6 y 12 alumnos indicaron estas edades respectivamente), quedando el $76,4 \%$ de la muestra concentrada en el tramo de 18 a 21 años (el promedio de los alumnos fue de 20,16 años). Sobre las áreas de conocimiento de la matrícula de los alumnos - de acuerdo con la clasificación internacional normalizada de la educación (Unesco, 1997) — el 36\% correspondió a ciencias sociales, jurídicas, humanidades y comunicaciones; $12 \%$ a enseñanza comercial, $12 \%$ a agricultura, $11 \%$ a ciencias físicas, $10 \%$ a arquitectura y producción, $9 \%$ a medicina, $5 \%$ a ingeniería y profesiones afines y $5 \%$ a artes. Por otra parte, el $80 \%$ de los estudiantes indicaron haber cursado su enseñanza media en la ciudad de Santiago y el $20 \%$ en diferentes regiones del país. Finalmente, respecto a la situación económica de los encuestados, fue posible distinguir dos estratos generales: quienes pueden pagar la totalidad de sus estudios, con recursos propios o familiares, y quienes requieren créditos estatales especiales para el pago de sus aranceles. En nuestra muestra el $46 \%$ pertenece al primer grupo y el $54 \%$ al segundo.

Respecto a la lectura de los resultados, se asignó un valor numérico a cada espacio de distancia o peldaño entre los extremos del par adjetivo, lo que permitió la realización de su análisis estadístico. Para el análisis se recodificaron los valores de los peldaños entre pares de adjetivos, de manera que siempre el valor más alto se asociara al adjetivo de connotación positiva y el valor más bajo al adjetivo de connotación negativa. Con el fin de observar las tendencias de los estudiantes para evaluar los tres reactivos, se determinó que los puntajes 5, 6 y 
7 marcarían la tendencia hacia al extremo «positivo» del par adjetivo, el valor 4 representaría una posición neutral y los puntajes 1,2 y 3 señalarían la tendencia hacia el extremo «negativo» del par adjetivo. Por ejemplo, frente al par «independiente-dependiente», las puntuaciones 5, 6 y 7 indicarían una tendencia hacia el extremo «independiente», el puntaje 4 una posición neutral y los valores 1,2 y 3 una tendencia hacia el extremo «dependiente». Por otra parte, para afinar y enriquecer el análisis, se determinó que los valores 1,2 y 6, 7 indicarían tendencias extremas para el atributo (negativas/derecha y positivas/izquierda). Finalmente, se calcularon frecuencias de respuesta, porcentajes de las mismas, medidas de tendencia central y comparaciones entre porcentajes con una prueba de diferencia de proporciones (alfa: 0.05). La presentación de los análisis se hizo en forma de gráfi$\cos$ de barras que favorecen una percepción visual de las tendencias para cada reactivo, con sus similitudes y diferencias, en cada uno de los 16 pares de adjetivos.

\section{Resultados}

Como se observa en el gráfico, los resultados que arrojó la aplicación del diferencial semántico reflejaron tendencias comunes en las imágenes que tienen los jóvenes sobre la vejez. En efecto, pareciera ser que las variables consideradas en el estudio - género, procedencia y nivel socioeconómico - no estarían influyendo significativamente en las imágenes que los jóvenes construyen sobre esta etapa de la vida.

De acuerdo con la prueba de diferencia de proporciones aplicada, los jóvenes tienden a ver a los adultos mayores y ancianos más «conservadores» que a las ancianas. En primer lugar, llama la atención la tendencia de más del $68 \%$ de los encuestados a evaluar a los adultos mayores, ancianas y ancianos como «conservadores». Para el caso de las ancianas el $68,33 \%$ respondió con tendencia a los valores negativos, frente a los ancianos el $77 \%$ de la muestra los ubica cerca del extremo «conservador» y el $76 \%$ tiende a considerar que los adultos mayores son personas «conservadoras».

Es importante destacar que, en proporciones iguales o mayores al $50 \%$, los entrevistados ubicaron sus respuestas para este atributo entre los valores 1 y 2 del diferencial semántico, es decir en las puntuaciones extremas, lo cual refleja la fuerza y peso que esta imagen tiene en los jóvenes. 
Gráfico 1

Comparación de tendencias obtenidas para Adulto Mayor, Anciana y Anciano

(Los valores positivos representan el porcentaje de tendencia hacia el polo positivo. Los valores negativos representan el porcentaje de tendencia al polo negativo)

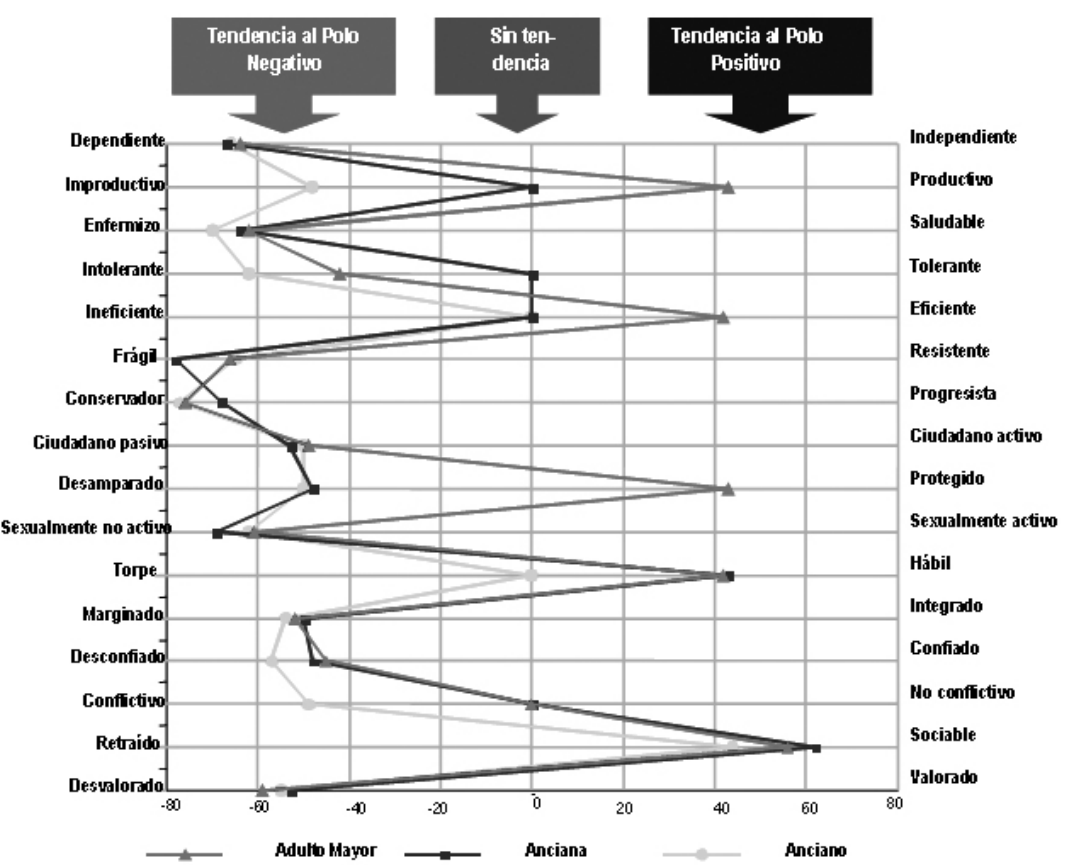

Respecto de la sexualidad, aún cuando a los adultos mayores, ancianas $\mathrm{y}$ ancianos se les atribuye una marcada tendencia a la inactividad sexual, las ancianas representan fuertemente esta imagen lo que las diferencia significativamente de los adultos mayores y de los ancianos. Un $69 \%$ de los encuestados tendió a considerarlas «sexualmente no-activas», mientras que la tendencia a considerar a los ancianos como «no-activos» fue de un $62 \% \mathrm{y}$, para el caso de los adultos mayores, de un $61 \%$.

Es interesante considerar que al observar las puntuaciones extremas del polo «sexualmente activo» (puntuaciones 6 y 7) se advierte que los adultos mayores se diferencian significativamente de los an- 
cianos y ancianas al ser avaluados como más activos sexualmente, con un $9 \%$ de respuestas versus el $5 \%$ y $6 \%$ para las ancianas y ancianos, respectivamente.

Se observa un consenso entre los jóvenes para calificar tanto al adulto mayor, a la anciana y al anciano, como personas «enfermizas», «frágiles», «marginadas», «desvaloradas socialmente» y «dependientes». Estas imágenes pueden relacionarse tanto con la idea de una pérdida de la vitalidad física («frágil», «dependiente», «enfermizo»), como con la impresión de una progresiva desvinculación de la sociedad («marginado», «desvalorado socialmente»).

Frente al par adjetivo «saludable-enfermizo», si bien en general se percibe a los adultos mayores, ancianas y ancianos como personas enfermizas, los ancianos son los peor evaluados con una tendencia de un $70 \%$ que los considera «enfermizos», diferenciándose de las ancianas y adultos mayores, quienes muestran una tendencia del $64 \% \mathrm{y}$ $62 \%$, respectivamente.

Respecto del par «frágil-resistente» el $66 \%$ de los encuestados ubica a los adultos mayores cercanos al polo de «frágiles», un $65,25 \%$ lo hace para los ancianos y el 77,71\% atribuye esta característica a las ancianas, quienes son vistas como más frágiles que los otros dos grupos.

En cuanto a la «integración» social, la tendencia a considerar a los adultos mayores como personas «marginadas» es del 52\%; el 50\% lo estima para las ancianas y el $54 \%$ lo hace para los ancianos, diferenciando a estos últimos de los otros dos grupos al ser considerados como personas más «marginadas» socialmente.

En relación a la imagen de valoración o desvalorización de la vejez, se observó una tendencia del 59\% a considerar a los adultos mayores como personas socialmente «desvaloradas», la tendencia para las ancianas fue del $53,23 \%$ y $55 \%$ para los ancianos.

Se aprecia en los jóvenes una marcada tendencia, entre el $64 \%$ y $67 \%$, a evaluar a los tres grupos como personas «dependientes». Aho$\mathrm{ra}$, al revisar las puntuaciones extremas, llama la atención que el anciano es considerado como «independiente» por un porcentaje significativamente menor en comparación a las ancianas y adultos mayores en sus puntajes extremos (6 y 7).

Respecto de los pares de atributos «ciudadano activo-ciudadano pasivo», se observó, entre un $49 \%$ y $53 \%$, una tendencia a considerar a las tres categorías de personas como «ciudadanos pasivos». Ahora bien, las puntuaciones extremas positivas ( 6 y 7 ) diferencian significativamente a los adultos mayores de las ancianas y ancianos para el 
atributo «ciudadano activo» con un 32\% de respuestas para estos puntajes extremos frente al $29 \%$ obtenido tanto por las ancianas como ancianos.

En cuanto al par «protegido-desamparado», la tendencia fue a evaluar como «desamparados» a los ancianos y ancianas, observándose porcentajes de entre un 31\% y 50\% respectivamente. Sólo los adultos mayores fueron considerados como personas «protegidas» $(43 \%)$.

Aún cuando en general los adultos mayores, las ancianas y los ancianos son evaluados negativamente, hubo diferencias interesantes para el par adjetivo «productivo-improductivo». Se observó una tendencia a considerar a los adultos mayores como personas «productivas» $(43 \%)$, diferenciándose significativamente de los ancianos, quienes presentaron una tendencia hacia el polo «improductivo» de un $48 \%$ y de las ancianas, las que no fueron evaluadas con una tendencia clara hacia ningún polo del atributo.

Estas diferencias podrían relacionarse tanto con variables de género como con las edades atribuidas por los encuestados al adulto mayor, anciana y anciano. En nuestro país muchas de las actuales ancianas no desarrollaron durante su juventud y adultez una actividad remunerada, que generalmente se asocia con «productividad», lo que puede explicar la falta de una tendencia clara en este atributo para ellas.

También frente al par adjetivo «eficiente-ineficiente» en el reactivo adulto mayor se observó una tendencia clara y positiva en las respuestas, con un $41,6 \%$ cercano al polo «eficiente» y un $25,7 \%$ al polo «ineficiente». Para las ancianas y ancianos la prueba de diferencia de proporciones no arrojó diferencias intra-grupo, por lo que no es posible hablar de tendencias en las respuestas referidas a estos dos reactivos.

Es interesante destacar que, en general, el anciano representa al grupo peor evaluado en la prueba, ya que además de atribuírsele las mismas características negativas que a los otros dos reactivos, es visto como una persona más «intolerante», «desconfiada» y «conflictiva» que las ancianas y adultos mayores, diferenciándose significativamente de estos dos grupos.

Debemos destacar también, que en el par adjetivo «no conflictivo-conflictivo» sólo para el reactivo anciano los jóvenes mostraron una tendencia negativa clara en su evaluación, al considerarlo cercano al polo «conflictivo» $(48,53 \%)$. 
Si bien, en la mayoría de los pares adjetivos las tendencias asignan a la vejez los atributos negativos, para el par adjetivo «hábiltorpe», tanto los adultos mayores como las ancianas mostraron tendencias hacia el extremo «hábil» ( $42 \%$ y $43 \%$, respectivamente). Para el caso de los ancianos, de acuerdo con la prueba de diferencia de proporciones, no se observó una tendencia hacia ninguno de los extremos del par adjetivo.

Solamente en el par adjetivo «sociable-retraído» los tres grupos fueron mejor evaluados. Un $56 \%$ evaluó a los adultos mayores cercanos al polo «sociables». Lo mismo ocurrió con las ancianas, evaluadas con una tendencia del $61,58 \%$ hacia este extremo. Por su parte, los ancianos también fueron evaluados positivamente pero con una tendencia del $44,28 \%$ de respuestas.

En síntesis, si bien se observaron algunas tendencias a evaluar positivamente a los adultos mayores, ancianas y ancianos, las imágenes que los jóvenes construyen en torno a la vejez tienden a ser, para la mayoría de los pares de adjetivos, negativas, aún cuando se perciben algunas diferencias en el «nivel o grado» de negatividad frente a algunos adjetivos para los tres reactivos. Esto confirma que, pese a las diferencias encontradas, los estereotipos sobre la vejez están fuertemente marcados por evaluaciones negativas en las atribuciones de los jóvenes encuestados.

Finalmente, los tres grupos presentan algunas diferencias significativas en las tendencias positivas, quedando las ancianas como las mejor evaluadas, seguidas por los adultos mayores y luego por los ancianos.

\section{CONCLUSIONES}

Nuestros resultados son consistentes con los obtenidos en varios de los estudios revisados, particularmente con aquellos pertenecientes a la cultura occidental. Hemos constatado que las atribuciones que aplican los jóvenes chilenos a la vejez apuntan a una idea de decadencia. Esta decadencia puede ser interpretada como otra consecuencia no esperada de nuestros procesos de modernización, como es el caso del aumento promedio de la esperanza de vida al nacer, y que finalmente se traduce en la exclusión social para este grupo etario. Este proceso se desarrolla a partir de un vacío de roles positivos, comúnmente denominado «muerte social» y en sentimientos de soledad, término usado muchas veces por los mayores para describir lo que podría ser de- 
finido como síntomas depresivos (Barg et al., 2006). Estos efectos se multiplican en tanto las solidaridades intergeneracionales entran también en crisis.

Podemos concluir que la mayoría de los jóvenes encuestados perciben la vejez como una desgracia. Posiblemente ello tenga relación con la sobrevaloración que hoy en día se tiene de la juventud. En una sociedad donde la realización personal se asocia al éxito y éste es vinculado al logro de estatus y dinero, las capacidades competitivas, atribuidas mayoritariamente a los jóvenes y adultos jóvenes, son vistas como centrales para acceder a la felicidad.

Sin proponérselo, los jóvenes bajo estudio generalizan estereotipos que no se empalman con las actuales posibilidades de los adultos mayores y que, por el contrario, estimulan la resignación y el fatalismo. Aparentemente, para estos jóvenes, la vejez provocaría angustia o vergüenza. Sin duda, gran parte de estas impresiones se recogen desde imágenes que circulan en la sociedad, las cuales presentan como adultos exitosos a aquellos que parecen o luchan por no envejecer. Todo lo anterior contribuye a la configuración de un entorno social que tiene mucho de geronto y gerascofóbico, en donde predominan actos discriminatorios frente a las personas consideradas como «viejas»y temores manifiestos ante el propio envejecimiento.

Los estereotipos contenidos en las imágenes sociales indicadas, condicionan a los ancianos a aceptar «una realidad» montada sobre prejuicios que finalmente hacen suya, padeciendo las consecuencias de ello. En este contexto no es extraño que muchas de las personas que se aproximan a la vejez se enfrenten a una lucha por aferrarse a las cualidades propias de una juventud y adultez joven idealizada, lo que les puede generar por consecuencia importantes sentimientos de frustración.

Importa señalar que estas ideas - expectativas y representaciones - pueden llegar a afectar la salud de los actuales adultos mayores, si éstos asimilan las imágenes que se les asocian como «condiciones normales para su edad» descuidan sus tratamientos y pierden la motivación por realizar los esfuerzos que requieren para mantener una vida saludable, con buenos niveles de bienestar físico y psicológico. Por ejemplo, y para el caso de la soledad, si bien no hay impedimentos para que los adultos mayores mantengan o retomen su vida amorosa, el contexto social juega en su contra dificultando la experiencia de disfrutarla. 
Finalmente, debe destacarse el hecho que los jóvenes tengan imágenes negativas y pesimistas sobre la vejez, no deja de ser también un importante problema para ellos mismos. Sus imágenes constituyen expectativas sobre sus propios futuros: los jóvenes también envejecerán y deberán enfrentar esa etapa con sus propios estereotipos, aquellos que hoy reproducen. Como señalan Holstein y Minkler (en Hendricks y Russell, 2006:310) «the power of unexamined cultural images subtly invades consciousness even when prejudicial to the person internalizing them ... older people try to become what culture signals as desirable without always recognizing where the pressures originate and even if those efforts are ultimately self-defeating». Paradojalmente, los jóvenes quieren y pueden vivir más años que sus ancestros, pero no desean ser ancianos. Es en este sentido que afirmamos que el envejecimiento de nuestra población se sustenta sobre estructuras sociales y representaciones que le dan la espalda a estos procesos.

Por lo señalado, creemos que comenzar a develar las imágenes que predominan en nuestra sociedad sobre la vejez puede resultar un aporte a su reflexión y cuestionamiento, lo que constituye un paso en la dirección de cambiarlas y con ello mitigar los efectos no deseados de las representaciones que prescriben normas de comportamiento que restringen las efectivas posibilidades de los que envejecen.

SANTIAGO (CHILE), MARZO 2007

RECIBIDO: ABRIL 2007

ACEPTADO: JUNIO 2007

Investigación desarrollada en el marco del proyecto Anillos de Ciencias Sociales patrocinado por la Comisión Nacional de Ciencia y Tecnología (CONICYT) y el Banco Mundial. Este artículo contó con la colaboración de las sociólogas Florencia Jensen y Natalia Vogel, asistentes de investigación del Programa de Magíster en Antropología y Desarrollo de la Universidad de Chile, y la asesoría de Tamara Arnold como analista cuantitativa.

\section{REFERENCIAS BIBLIOGRÁFICAS}

Adelantado, F.; C. Segura, J. De Andrés, T. Feliu y P. Martínez (2004): «Los mayores de 85 años en Sabadell» Revista Multidisciplinar de Gerontología Volumen 14, No5. 
Aguilera, M. (2005): «Las nuevas proyecciones de población». Santiago: INE. ARNOLD, M. (2003): «Fundamentos del constructivismo sociopoiético». Cinta de Moebio $\mathrm{N}^{\circ} 18$. Santiago: Universidad de Chile.

Barg, F.; R. Huss-Ashmore, M. Wittink, G. MurRay, H. Bogner, H. y J. GALLO (2006): «A Mixed-Methods Approach to Understanding Loneliness and Depression in Older Adults». Journal of Gerontology: Social Sciences Vol. 61B, №6.

BRAVO, J. y F. BERTRANOU (2006): «Evolución demográfica y pensiones en Chile». OIT Notas $\mathrm{N}^{\circ} 4$.

FeIXA, C. (1996): «Antropología de las edades». En J. PrAT y A. MARTíneZ (editores): Ensayos de antropología cultural. Barcelona: Ariel.

GÓMEZ CARROZA, T. (2003): «Heteroestereotipos y autoestereotipos asociados a la vejez en Extremadura». Tesis Doctoral. Universidad de Extremadura, Facultad de Formación del Profesorado, Departamento de Psicología y Sociología de la Educación, Cáceres.

HENDRICKS, J. y H. RUSSELl (2006): «Lifestyle and Aging». En R. BINSTOCK y L. GEORGE (editores): Handbook of Aging and the Social Sciences. Amsterdam: Academic Press.

INFORME DEL COMITÉ NACIONAL PARA EL ADULTO MAYOR (2002): «Encuesta imagen de la vejez». Santiago.

INE/CEPAL/CELADE (S/F): «Chile: proyecciones y estimaciones de población. Total país 1950-2050». En: www.ine.cl.

LuHManN, N. (1998): Die Gesellschaft der Gesellschaft, Suhrkamp Taschenbuch Wissenschaft 1360, Suhrkamp Taschenbuch Verlag, Frankfurt am Main.

OKOYE, U. (2004): «Knowledge of aging among secondary school students in south-eastern Nigeria». Educational Gerontology $\mathrm{N}^{\circ} 30$.

OsGood, Ch.; G. J. SucI y P. H. TANNENBAun (1957): The Measurement of Meaning. Urbana: University of Illinois Press.

PINTOS, J. (2004): «Comunicación, construcción de realidad e imaginarios sociales». En www.gceis.org.

UC-ADIMARK (2006): «Encuesta nacional bicentenario». Santiago: UCAdimark.

Puijalon, B. y J. TRINCAZ (1999): «El espejo de la sociedad». El Correo de la UNESCO 1999. En: www.unesco.org.

TAN, P.; N. ZHANG y L. FAN (2004): «Students' attitudes toward the elderly in the people's republic of China». Educational Gerontology $\mathrm{N}^{\circ} 30$.

UNESCO (1997): «Clasificación Internacional Normalizada de la Educación». En: www.unesco.org.

YounG, M. y T. Schuller (1993): «Life after Work: The Arrival of the Ageless Society». The British Journal of Sociology Volumen 44, №2.

ZiKmund, W. (1998): Investigación de mercados. México: Pearson Prentice Hall. 